\title{
PARA UNA ESTÉTICA DE LA VIDA COTIDIANA: NATURALEZA, POTENCIA Y CUERPO EN SPINOZA Y MARX
}

For an every day life aesthetic: Nature, potency and body in Spinoza and Marx

\author{
DANIELACÁPONA GONZÁLEZ \\ Universidad de Chile \\ dcapona@gmail.com
}

Resumen

En el presente artículo se analizan y vinculan las nociones de naturaleza, cuerpo y potencia a partir de Spinoza y Marx, en virtud de los cuales se plantea que la exteriorización del hombre y su esencia es no solo social, sino productiva en el sentido de praxis y actividad de sí mismo y lo social. En este sentido, este acto de producción en el mundo contemporáneo está enmarcado en la experiencia cotidiana de habitar la ciudad, la cual, bajo el alero del capitalismo, ha sido reducida a una estética del hábitat a partir de procesos de dominación material y subjetiva, que ostentan la estandarización de las prácticas sociales, escindiendo la potencia del hombre, invirtiendo el orden afectivo y por tanto escindiendo la corporalidad y el ámbito cognitivo de los hombres.

Palabras clave: Estética de la vida cotidiana; potencia; cuerpo, praxis, afectividad.

Abstract

In the present article it will be analysed and associated the concepts of nature, body and potency based on Spinoza and Marx, from this point it will be suggest that the act of man' exteriorization (and his essence) it's not only social, but also productive in the sense of praxis and activity of itself and of social. In this sense, this creative act is based in the contemporary world in the daily experience of inhabit the city, the one, under capitalism, is been reduced to an habitat'aesthetic, by process of material and subjective domination which pretend the social practices' standardization, separating man's potency, inverting the affective order and, by conclusion, separating corporality and the cognitive sphere of men.

Key words: Every day life'aesthetic; potency; body; praxis; affectivity

Los Manuscritos de economía y filosofía de Marx escritos en 1844 en su estadía en París, pero publicados recién en 1932, son textos usualmente relegados por tratarse aún de la etapa de juventud del pensamiento del alemán, que no tendrían el aparataje científico que adquiriría en sus escritos de madurez, como lo es El Capital. Sin embargo, lecturas más recientes han podido vincular los planteamientos filosóficos del joven Marx con su obra tardía. Los textos que escribe entre estos años, como La sagrada familia (1844), La ideología alemana (1845) -ambos escritos con Engels-y las llamadas Tesis sobre Feuerbach (1845, publicado y editado por Engels en 1888, conociéndose el original en 1931) son producto de un posicionamiento de Marx respecto de la filosofía anterior, idealista, hegeliana y poshegeliana respecto de su propio pensamiento. Por ello 
es que Osvaldo Fernández (2017) recalca que "tanto sus primeros artículos en los Anales Franco alemanes como los gruesos volúmenes de La sagrada familia y La ideología alemana, pasarán a ser el campo de batalla de este doble enfrentamiento; con los filósofos alemanes, pero también y al mismo tiempo consigo mismo" (pp. 17-18).

Conceptos como ser genérico, fuerza de trabajo, naturaleza inorgánica, alienación, permiten ver una noción antropológica en Marx, que en su desarrollo implican el establecimiento de una ontología del ser social, al mismo tiempo que una teoría de la sensibilidad y de la potencia. Es a partir de esto que es inevitable no pensar en Spinoza y en la posibilidad de una conjunción teórica, situando a ambos en el horizonte de lo contemporáneo, como diría Agamben (2014, pp. 28-29). En el presente artículo se analizarán los conceptos de cuerpo, sensibilidad, potencia y naturaleza entre Spinoza y Marx -a partir de la Ética del filósofo holandés, y los Manuscritos de economía y filosofía, con sus textos aledaños, del alemán-, con el objetivo de poner en la palestra la existencia de una forma determinada y negativa en la que el hombre actúa, padece y vive. Cuando Deleuze recalca la sentencia spinozista que indica: "nadie, hasta ahora, ha determinado lo que puede el cuerpo" de E, III, Prop. II, esc. (Spinoza, 2009, p. 97), critica no solo la sobreposición de la conciencia a la corporalidad y también su escisión, sino que además realiza un llamado de atención al desconocimiento de la lógica propia de la corporalidad, desconocimiento que lleva a la imaginación y, por tanto, a estar sujeto a relaciones de dominación que se expresan en el orden tanto de la subjetividad como de la sensibilidad, en cuanto sujeción a una estandarización de las prácticas sociales. Esto implica que hay una estética operando en la forma en que el cuerpo se despliega en el espacio, la que está mediatizada por la relación de este con la naturaleza y la sociedad. De esta manera, si el espacio es un producto social, como afirma Henri Lefebvre (2013, p. 86), esta producción se encuentra determinada por la misma denegación de la potencia de los hombres en su acto productor, es decir, los hombres que en sociedad producen el espacio son los mismos que, determinados por el poder del capital y en un acto de destrucción creativa, producen un espacio coercitivo y disgregador respecto de su propia potencia, en donde configuran su vida cotidiana.

Si bien la vida ha sido siempre objeto de la reflexión filosófica, la formulación específica de vida cotidiana ha cobrado mayor relevancia durante el siglo XX, en donde destacan Agnes Heller y Henri Lefebvre, filósofos que, desde el marxismo, pudieron elaborar sus propias teorías fundamentados en el materialismo histórico y en la particularidad de los hombres concretos, viendo a la vida cotidiana como realidad social y desde su operatividad en la constitución de la individualidad social. Michel de Certeau será otro gran exponente en este tópico, influenciado por Lefebvre en lo que respecta al rol de la praxis, pero elaborando su propio pensamiento desde el ámbito de la historia, la cultura y el psicoanálisis. En vereda opuesta está la fenomenología de Heidegger, quien mencionó de forma menor este término en Ser y tiempo pero desde la impropiedad, pero 10 | Alpha No49 (Diciembre 2019) PÁGs. 9-24. ISSN 07 16-4254 
Para una estética de la vida cotidiana: Naturleza, potencia y cuerpo en Spinoza y Marx

que también a partir de las nociones fenomenológicas del habitar y construir, posibilitarán una cierta discusión en torno a este tópico. Así, desde un prisma fenomenológico, el filósofo chileno Humberto Giannini escribe La 'reflexión' cotidiana: hacia una arqueología de la experiencia (ver Santos Herceg, 2014, pp. 173-177). Se podría decir que en mayor o menor medida, la vida cotidiana siempre es objeto de pensamiento, pero desde un prisma no filosófico, es decir, estando en un constante desplazamiento. Los análisis de Spinoza y Marx comulgan en un punto vital para considerar la vida cotidiana que es la experiencia, sea desde los afectos en el caso del primero, como del trabajo en el caso del segundo, para pensar una vida libre. Se trata de pensar cómo los hombres en su constitución afectiva se exteriorizan mediante la praxis, determinando formas sensibles de habitar el espacio y vivir la cotidianidad arraigados a su propia producción. Se trata en este punto de ver la particularidad de hombres concretos sometidos a regímenes de determinación extrínsecos, como la economía-política del capital o la dominación teológico-política, y su configuración sensible en la vida cotidiana.

\section{NATURWESEN Y PARS NATURAE: NATURALEZA Y SOCIEDAD EN MARX Y SPINOZA}

Marx (2010) para hablar del hombre como ser social en los Manuscritos de economía y filosofía debe necesariamente partir por el concepto de naturaleza. Para esto se retrotrae a la concepción que hereda del humanismo/naturalismo de Feuerbach con su teoría del ser genérico. Del filósofo alemán adquiere -al mismo tiempo que critica y supera- una visión sensualista de la naturaleza y una teoría de la objetividad como constitutiva del hombre. Siguiendo a Feuerbach: el hombre se conoce en el objeto, en su interacción con él; aquí radica la raigambre materialista de Marx, pero en una versión radicalizada respecto de la de su antecesor. En La esencia del cristianismo, el filósofo afirma que, "cualquiera que sea el objeto que se presente a nuestra conciencia, siempre nos hacemos al mismo tiempo conscientes de nuestra propia esencia; no podemos activar otra cosa, sin activarnos al mismo tiempo también a nosotros mismos" (Feuerbach, 2006, p. 18). Todo conocimiento de la propia esencia se da en un objeto exterior, es en y por los objetos que el hombre puede reconocerse a sí mismo como hombre, es por ello que el ser humano es un ser con objetos, allende ellos, su existencia se remite a la animalidad. La diferencia entre ambos seres es que el hombre pone su vida como objeto de su propia existencia, esto implica que la subjetividad como conciencia individual es siempre secundaria a las relaciones esenciales que el hombre establece respecto de los objetos, pues son ellos los que motivan la producción como praxis. Es en virtud de la sensibilidad en sus necesidades básicas y elementales, como el hambre, la sed, las que permiten que el hombre componga una relación con un objeto -la comida, el agua-que permite no solo la satisfacción de una carencia, sino que además, se conozca a sí mismo por la mediación de los objetos. Esto mismo quiere expresar Spinoza cuando afirma en E, II. Prop. XVI. Cor. I y II. que: "el alma humana percibe, junto con la naturaleza de su 
propio cuerpo, la de muchísimos otros" y "las ideas que tenemos de los cuerpos exteriores revelan más bien la constitución de nuestro propio cuerpo que la naturaleza de los cuerpos exteriores" (p. 139). Lo que comparece en ambas visiones es la del hombre como ser objetivo, como ser entre objetos, desplazando de esta forma todo idealismo y subjetivismo en la comprensión del hombre; bajo este respecto, no hay jerarquía ontológica que separe al hombre de los objetos, pues ambos tienen un vínculo esencial en y por la naturaleza. Es por ello que para Spinoza, como dice en E, II, Prop. XXII, "el alma humana percibe, no solo las afecciones del cuerpo, sino también las ideas de esas afecciones" (p.147) y también que "el alma no se conoce a sí misma sino en cuanto percibe las ideas de las afecciones", como dirá en la proposición siguiente (p.147). Pero cabe la precisión de que, "la idea de una afección cualquiera del cuerpo humano no implica el conocimiento adecuado del cuerpo humano mismo" (p. 151), y que además, "las ideas de las afecciones del cuerpo humano, en cuanto referidas solo al alma humana, no son claras y distintas, sino confusas", como ha escrito en E, II, Prop. XXVII y XXVIII (p. 151). Es decir, el conocimiento se da solo en la medida en que el cuerpo está sujeto a afectos de los cuerpos exteriores, sin embargo, tal conocimiento no es inmediatamente adecuado. La idea del hombre como ser-entre-objetos implica una reconsideración del concepto naturaleza, la que es concebida por Marx, tal como afirma Alfred Schmidt (1977), no como una categoría metafísica, sino como una inmanente, tal como para Spinoza. En el objeto, el hombre se comprende como ser genérico, hace de su género (y no de su individualidad) el objeto de su conciencia. Por este motivo Marx (2010) afirma: "que la vida física y espiritual del hombre está ligada con la naturaleza no tiene otro sentido que el de que la naturaleza está ligada consigo misma, pues el hombre es una parte de la naturaleza" (pp. 111-112).

El hombre, en tanto parte de la naturaleza, siempre tendrá un vínculo intrínseco de codependencia respecto de ella. Por ello, Marx la concibe como el cuerpo inorgánico del hombre, es decir, como su propia extensión, sin esta, no cabría lugar para ningún tipo de praxis. En este sentido, la naturaleza para ser tal ha de estar mediatizada por el hombre, y el hombre para ser tal depende de su relación con esta, en cuanto a partir de la transformación que este ejerce sobre ella, puede producir y producirse a sí mismo. Y es así porque Marx comprende la producción tanto en el ámbito de la actividad vital del hombre, como reproducción de los medios de su propia reproducción en cuanto valor de uso, como también la producción de mercancías, fenómeno propio de la sociedad burguesa. Sin embargo, la producción también puede comprenderse como la de sí mismo, en cuanto su vinculación con la naturaleza implica también su propia transformación: la activación de la naturaleza es a la vez la activación de sí. Esto desde las formas más elementales, como la constitución de los sentidos: "la formación de los cinco sentidos es un trabajo de toda la historia universal hasta nuestros días. El sentido que es presa de la grosera necesidad práctica tiene solo un sentido limitado" (Marx, 2010, p. 146). De lo que Marx desprende también que la vida humana se define por la actividad productiva: 12 | Alpha No49 (Diciembre 2019) PÁGs. 9-24. ISSN 07 16-4254 
Para una estética de la vida cotidiana: Naturleza, potencia y cuerpo en Spinoza y Marx

"La vida productiva es, sin embargo, la vida genérica. Es la vida que crea vida. En la forma de la actividad vital reside el carácter dado de una especie, su carácter genérico, y la actividad libre, consciente, es el carácter genérico del hombre" (p. 112). Esta actividad vital el hombre la obtiene mediante el trabajo, pero un tipo específico de este, el particular concreto, no aquel general abstracto que impone la sociedad burguesa. Esto implica que lo esencial para que el hombre se constituya como tal es la objetividad, no solo en la interacción con la naturaleza, sino más aún, su transformación: la elaboración del mundo como producto humano, un producir que es siempre un produciendo. En palabras de Carlos Casanova, es una "recíproca pertenencia de praxis y "vida de género» (Gattungsleben): ambas se pertenecen en un círculo, en el interior del cual la una es origen y fundamento de la otra; praxis y vida común, en otras palabras, mantienen una relación co-constituyente" (Casanova, 2016, p. 33). La esencia del hombre, por esta razón no es abstracta, pues esta se constituye en virtud de la construcción por parte del hombre -como su activación- del mundo objetivo, de la transformación de la naturaleza en un cuerpo inorgánico, debido a que el hombre se define no solo como un ser natural, sino ante todo, como un ser social.

La relación que entabla la naturaleza como cuerpo inorgánico del hombre tiene un carácter determinado: es siempre de índole social, precisamente porque pone a su género en su universalidad, como objeto de su conciencia. En este sentido acierta la visión de Lukács, quien ve la naturaleza como una categoría social, sin embargo, no puede reducirse solo a esa determinación, pues como afirma Schmidt (1977), esa visión es otorgarle un rol subjetivo como "productor" (p. 78). La naturaleza no puede diluir su carácter objetivo en el subjetivo, sino que para Marx, como sigue Schmidt, la naturaleza siempre mantiene su carácter objetivo de exterioridad. Por consiguiente, la naturaleza es tanto una categoría social como una categoría natural (Fischbach, 2014, p. 77). Aquí se vuelve a afirmar el carácter relacional social de la esencia del hombre, de allí que en la sexta de las Tesis sobre Feuerbach Marx afirme: "Pero la esencia no es algo abstracto e inmanente a cada individuo. Es, en su realidad, el conjunto de las relaciones sociales" (Marx, 1970, p. 667). Es decir, se conciben como parte-de, como un ser-con, y nunca como una sustancia autónoma. Carlos Casanova expresa esta vinculación:

La "esencia genérica" de los hombres, su Gattungwesen, no es otra cosa, así pues, que la vida en tanto que apariencia, en tanto que potencia originariamente ofrecida al goce y al uso común (...) la vida es el ser común e insustancial: la simultaneidad del estar-juntos de los individuos o la Humanidad como el "mundo de los hombres". El uso o praxis de ese común es lo que constituye la historicidad esencial de estos (Casanova, 2016, p. 29).

En términos spinozistas, se trata de concebirse como un modo finito, los que dependen de la sustancia para expresar su potencia, en cuanto esta es "aquello que es en sí y se concibe 
por sí, esto es, aquello cuyo concepto, para formarse, no precisa del concepto de otra cosa" (Spinoza, p. 46), como afirmar en la definición III de E, I. De esto se sigue que todo modo, en cuanto afección de la sustancia, es equivalente, pues no hay jerarquía ontológica que determine un valor superior de uno respecto del otro. Los modos se establecen en un plano inmanente, en donde la sustancia única, como pura productividad en cuanto causa sui, expresan cualitativa y cuantitativamente su potencia; el modo es un quantum de esta potencia productiva que se expresa, y por tanto, su naturaleza lo llama siempre a potenciar su conatus. La famosa sentencia Deus sive Natura es la radical afirmación que enlaza directamente a los hombres, como modos finitos, en un lazo de codependencia respecto de la naturaleza: el modo finito es esencialmente una pars naturae. Incluso en la distinción formal que realiza Spinoza al hablar de una natura naturans (la naturaleza como productora) y una natura naturata (que corresponde al orden de lo producido), no hace sino distinguir la doble lógica de la naturaleza, pero nunca su escisión. Tal como afirma Fischbach: "La naturaleza es inmanente y no exterior a su propia actividad productiva, y ella no puede, por tanto, ser sujeto: eso, en términos spinozistas, viene a decir de otra forma que la natura naturans (...) es idéntica a la natura naturata (...)" (Fischbach , 2014, p. 148). Lectura que avala a partir de E, I. Prop. XVIII, en donde Spinoza afirma que: "Dios es causa inmanente, pero no transitiva, de todas las cosas" (p. 73), lo que significa que la naturaleza, o Dios, no puede concebirse nunca como sujeto, en cuanto escindido del mundo de los modos, y por esto, tampoco de la objetualidad y de la naturaleza. Fischbach afirma: "si Marx ha recibido cualquier cosa de Spinoza, nos parece ser precisamente su concepción de la substancia, en cuanto ella implica una ontología de la producción o de la actividad como actividad infinitamente, naturalmente, necesariamente y materialmente productiva" (Fischbach, 2014, p. 33).

Cuando Marx establece la relación entre el hombre y la naturaleza, instaura una ontología relacional en la que el hombre se realiza a sí mismo en sus relaciones con la naturaleza y la sociedad. El hombre al establecer estos vínculos compone relaciones, en el mismo sentido en que para Spinoza el modo finito compone relaciones - que aumentan como disminuyen la potencia de obrar-con los cuerpos exteriores.

\section{CUERPO Y SENSIBILIDAD: SUBJETIVIDAD, ALIENACIÓN E IMPOTENCIA EN SPINOZA Y MARX}

El problema surge cuando el hombre se ve enfrentado a la naturaleza como algo externo a él, en donde se encuentra extrañado y separado de sus objetos esenciales, es decir, de su mundo objetivo. Este fenómeno ocurre con la aparición de la sociedad moderna y la industria -la que es también un producto socio-histórico natural-, fenómenos que conllevan la formulación e imposición del trabajo general-abstracto. El suceso que acaece en virtud de estos dispositivos es la enajenación o alienación. La enajenación del hombre de su relación con la naturaleza es lo que le permite concebirse 
a sí mismo como un sujeto, lo que bajo la óptica de Fischbach implica un cambio radical, pues: "devenir sujeto es esencialmente una reducción a la impotencia" (Fischbach, 2014, p. 21). Lo que es efectivamente cierto, en la medida en que, tal como afirma Marx: "En general, la afirmación de que el hombre está enajenado de su ser genérico quiere decir que un hombre está enajenado del otro, como cada uno de ellos está enajenado de la esencia humana" (Marx, 2010, p. 114). Desvincular al hombre de su mundo objetivo, de sus objetos esenciales, es desvincularlo de la sociedad, de su alteridad, que es tanto la naturaleza misma, como la sociedad que es producto de su actividad o praxis como ser genérico. Ya que, como define Marx, "la sociedad es, pues, la plena unidad esencial del hombre con la naturaleza, la verdadera resurrección de la naturaleza, el naturalismo realizado del hombre y realizado humanismo de la naturaleza" (p. 141).

Con la aparición de la sociedad burguesa y sus derechos - que permite la separación entre el hombre y el ciudadano- aparece también un tipo de subjetividad, que Mezzadra corresponde a la del burgués o capitalista contra la del trabajador o proletario. Pero la subjetividad misma, bajo la lectura de Mezzadra, es la propia enajenación. Es esta lo que hace al hombre un ser alienado de su ser genérico, pues no solo lo escinde de su espectro social y natural, sino que además lo hace situarse como sujeto individual. El filósofo italiano define las dos caras que tiene el concepto de subjetividad:

La historia moderna de este concepto, de hecho, se desarrolló en un equilibrio inestable inscripto en la misma etimología latina, es decir, por la combinación del neutro subjectum -traducción del griego hypokeimenon ("soporte") y que progresivamente se cargó de funciones de "comando", tanto en la ontología como en la gramática- y el masculino subjectus, considerado en la Edad Media como sinónimo de subditus y vinculado, luego, a una larga historia de sujeción y de obligaciones de obediencia (Mezzadra, 2014, p. 24).

De esta manera, la distinción entre hombre y ciudadano, propia de la sociedad burguesa, viene a delimitar el orden de los hombres en sociedad a partir del concepto de sujeto, el que es también sujeto de derechos, cuestión que Marx desarrolla en La cuestión judía (2011,p. 86). Esta distinción, como se puede deducir a partir de la lectura de Balibar, se relaciona con la disolución de la diferencia entre poiesis y praxis. La primera refería en la filosofía griega a una acción servil que remite a condiciones materiales, es decir, se trata de la producción de cosas. La praxis, por el contrario, remite a la acción libre del ciudadano como transformación de sí mismo (Balibar, 2000, p. 47). La potencia del hombre, por tanto, está unida a esta doble visión unitaria del producir: producción de sí mismo y producción de objetos para la reproducción material. El hombre debe reapropiarse de su potencia para quebrar la ilusión del sujeto, retomando su vínculo natural social para producirse a sí mismo a la vez que los medios que permiten su 
reproducción. Debe realizar una acción práctica para quebrar el espectro de la abstracción. Por ello es que:

Recién cuando el hombre individual real recobra en sí al ciudadano abstracto y como hombre individual se convierte en un ser genérico en su vida empírica, en su trabajo individual, en sus relaciones individuales, recién cuando el hombre ha reconocido y organizado sus forces propres como fuerzas sociales y, por lo tanto, ya no separa de sí la fuerza social bajo la forma de la fuerza política, recién entonces se lleva a cabo la emancipación humana (Marx, 2011, p. 87).

Ahora bien, lo importante de la teoría del ser genérico y lo expuesto anteriormente, es que implica una determinada visión antropológica centrada en el cuerpo, pero además, y a partir de esta, una teoría de la praxis que permite dilucidar, en el escenario actual, la forma en que la sensibilidad se ve expropiada de sí misma, en tanto que la exteriorización sensible se ve limitada a prácticas determinadas y estandarizadas. En este sentido, se trata de la imposición por parte del capitalismo de una estética del hábitat, en contra de lo que sería una estética del habitar, pues es habitando y produciendo el espacio donde el hombre revela en primer lugar su praxis creativa. En este sentido, se sigue con Adrián Scribano, que el trabajo como expropiación de energías es una de las formas en que se hace al hombre como uno a imagen del capital, es decir, "como actividad sensible de la cual se le enajena al hombre todo aquello que supere la mínima reproducción vital. La expropiación de energías es la base de una regulación sistemática de las sensaciones: la vida es pura disciplina fabril hecha carne" (Scribano, 2016, p. 11).

A esto se suma la consideración spinozista de la corporalidad, expuesta en el segundo libro de la Ética, en donde el filósofo holandés define el cuerpo como una composición de relaciones, cuyas leyes determinan tanto el cuerpo individual como colectivo -el Estado-, ya que "nada es más útil al hombre que el hombre", los que en su deseo por conservar su ser, han de "concordar todos en todas las cosas, de suerte que las almas de todos formen como una sola alma, y sus cuerpos como un solo cuerpo" (p. 307), como relata en E, IV. Prop. XVIII. Esc. Para Spinoza, la materialidad reside en la exteriorización del cuerpo en virtud de los afectos, cuya heteronomía le dota de un carácter plástico que se vincula directamente a una teoría de la potencia. Aquí, existe una articulación entre cuerpo y actividad cognitiva, y es donde se puede establecer una afinidad entre los planteamientos de este filósofo y los de Marx. A este respecto se puede aseverar con Fischbach (2014) que: "la física de los cuerpos conduce a Spinoza a una 'física social"' (p. 145).

Para Spinoza, toda imagen inflige un afecto a otro cuerpo, y por esto, realiza un cambio tanto en el cuerpo afectado como en el que afecta, es decir, muta la naturaleza corpórea al mismo tiempo que la cognitiva. Pero ¿qué es una imagen para Spinoza? En E, II, Prop. XVII, Esc. responderá que: 'Llamaremos 'imágenes' de las cosas a las 
afecciones del cuerpo humano cuyas ideas nos representan los cuerpos exteriores como si nos estuvieran presentes, aunque no reproduzcan las figuras de las cosas" (p. 141). Hay que considerar a su vez que, "las imaginaciones del alma, en sí mismas consideradas, no contienen error alguno" (p. 142). En virtud de esto, todo cuerpo, todo afecto, genera un conocimiento imaginativo del orden externo e interno; la imagen es, en definitiva, la primera forma en que se establece un estar-en-el-mundo. Y en este sentido, en la medida en que la imaginación como primer grado de conocimiento, y en virtud de la simultaneidad de estos mismos géneros, siempre permanece latente, incluso cuando hay un ascenso epistemológico a formas superiores. Ahora bien, ¿pueden las imágenes ser dispuestas artificialmente, de forma tal que estas se nos impongan, para lograr controlar los niveles de potencia, y por tanto, de cognición? Así es, y esta capacidad que tiene todo cuerpo de afectar y ser afectado se encuentra hoy mediatizada por una fabricación de afectos que buscan la impotencia del deseo -la esencia del hombre para Spinoza--, de modo tal, que se instaura una nueva geometría real y no ideológica de las pasiones, porque la imagen transforma la corporalidad y la mente humana, desplegando de esta forma ciertas estéticas del hábitat, como abstracción del habitar. Ahora bien, si la experiencia está inscrita en un régimen de prácticas limitado -en virtud de su estandarización y la introducción de cánones de vida-, entonces lo imaginativo se adecua a la forma en que se padece y actúa, dando espacio a que lo imaginativo pueda ser presa de una manipulación en distintas esferas, como en el espacio público, la publicidad, la arquitectura, entre tantas otras manifestaciones. Es decir, se constituye una regulación de las prácticas sociales a partir de las imágenes-afectos.

No obstante, ¿cómo se puede hablar de hábitat y habitar en Spinoza y Marx, siendo que son categorías o conceptos que ellos no trabajaron directamente? En la medida en que la potencia, la exteriorización y el carácter relacional que conlleva una determinación social en toda praxis o actividad humana, permiten pensar en estos conceptos desde la experiencia más elemental de la vida, el habitar. Las prácticas de los hombres en cuanto praxis y exteriorización de la potencia del hombre, como ser social, se configuran de determinadas maneras en virtud de cómo él es capaz de realizar tal proceso. En este sentido, y en cuanto hay sistemas de producción -en sentido amplio del término- que determinan esta capacidad inherente del hombre de constituirse a sí mismo y a su mundo objetivo, esta se altera y disloca de modo tal, que su praxis ya no es la propia de sí mismo, sino aquella que sirve a otro para llevar a cabo su cometido. Si bien este servilismo es necesario en cuanto permite la propia reproducción material, su alcance es mucho mayor y profundo que solo imponer un determinado patrón de existencia a nivel laboral, ya que la imposición del trabajo como uno abstracto se arraiga en una lógica trascendental que logra disolver la inmanencia del deseo. En esta medida, el trabajo abstracto con todo lo que implica, que es la venta de su fuerza de trabajo - es decir, configurándose a sí mismo como mercancía-, impone a su vez determinadas formas de habitar el espacio y de 
exteriorizar la potencia, formulando de esta manera una fábrica corporal y cognitiva de afectos/imágenes alegres que operan como sucedáneos de la verdadera alegría, aquella que potencia al deseo a afirmarse a sí mismo. De esta manera, la sensibilidad se ve coartada a una praxis determinada a la imagen del capital, que desencadena en una economía de la vida cotidiana y en una estética del hábitat.

No obstante lo anterior, no es malo ser afectado o padecer, ya que en ambos casos se genera un conocimiento, por consiguiente el alma percibe la idea del afecto, del cuerpo exterior y del propio cuerpo aunque sea de modo inadecuado, en virtud de ello se determina el orden cognitivo y de la praxis. Lo malo ocurre cuando este padecer implica un vaciamiento de la lógica afirmativa del deseo, es decir, cuando el deseo ya no posee la conciencia del esfuerzo que realiza por perseverar en su ser. Es decir, cuando los afectos ante los cuales el modo finito se ve enfrentado, son afectos alegres pero reducidos en su aspecto ontológico, porque se trata de un simulacro de alegría. El deseo como deseo del deseo es deseo de ser sui juris, es un deseo sin objeto, aun cuando se desea afirmar la potencia, situando en un segundo nivel el deseo por las cosas. Esto implica que la reducción de la alegría como aquello que aumenta la potencia es, en este marco de análisis, una alegría de imágenes que se sustentan en una visión economicista de la existencia. No tanto porque se desee, por ejemplo, tal o cual mercancía, sino porque la praxis y actividad se ve determinada a obrar de cierta manera, pese a que en el marco del capitalismo, los afectos también se introducen y mediatizan en virtud de la economía-política. Esta determinación y control de las pasiones se lograría por la configuración de un dispositivo que juega con la índole inadecuada de la imaginación, y que el mismo Spinoza ya habría identificado, y es que: "el hombre imagina necesariamente todo cuanto imagina que no puede hacer, y esta imaginación lo conforma de tal manera que realmente no puede hacer lo que imagina que no puede" (p. 271), como afirma en E, IIII. D.A. XXVIII. La potencia es determinada desde la imaginación, por un poder externo y trascendente que limita qué se puede y qué no se puede realizar, proponiendo alternativamente estos afectos de alegría fabricados como sucedáneos de la verdadera potencia sometida.

A su vez, esta misma fabricación implica una de otra índole, se trata de una fabricación de subjetividad. Se puede decir fabricación, en cuanto el trabajador vende su potencia productiva, y con ello, vende su individualidad, ya que inmediatamente este se encuentra determinado por la economía-política, la que disloca no solo su praxis y potencia, sino también la forma en que este se concibe a sí mismo, y por esta razón, también la forma en que este actúa y se posiciona en el mundo. La economía-política crea eimpone una nueva forma imaginativa de "estar-en-el-mundo" no solo alienada, sino también sujeta a órdenes de coalineación del deseo - en cuanto los deseos se ven determinados a alinearse a un deseo/amo, deseo/capital (Lordon, 2015, pp. 55-56) - y, además, a una subjetividad que hace que el hombre se conciba como una substancia dotada de libertad, pero libertad para consumir y para entrar en el mercado como mercancía.

18 | Alpha No49 (Diciembre 2019) PÁgS. 9-24. ISSN 07 16-4254 
Para una estética de la vida cotidiana: Naturleza, potencia y cuerpo en Spinoza y Marx

\section{PARA UNA ESTÉTICA DEL HÁBITAT EN SPINOZA Y MARX}

Configurar una estética a partir de Spinoza y Marx es establecer la forma en que la sensibilidad se determina en virtud de la estructuración de la corporalidad, a partir de la división del trabajo y su reformulación como uno abstracto, a lo que se suma la introducción del capitalismo en el ámbito de las imágenes del espacio público y privado, sea a nivel de la propaganda, monumentos, edificaciones, políticas públicas tanto de transporte como de viviendas sociales, formulando imágenes determinadas que afectan a los hombres y cómo estos actúan. Siguiendo a Carlos Casanova (2016), "la concepción antropológica en Marx es indivisible de una determinada concepción estética del hombre (...) el hombre es, según Marx, ese ser que solo existe en el modo de la praxis de sus sentidos, extrañado o apropiado, y confiado a lo posible en esas praxis de sí' (pp. 7-8).

A partir de esta perspectiva, y siguiendo a Casanova, estética en Marx se entiende como la manera en que el hombre existe como potencia, como praxis de sus sentidos y por esta razón, como praxis de sí. Ahora bien, ¿cómo plantear esta estética actualmente en el ámbito urbano, que es el espacio en donde los hombres se exteriorizan, en donde se padece actualmente una urbanización planetaria? Si la ciudad es el espacio en donde el hombre expresa su potencia y ejerce su praxis de los sentidos, es admisible preguntar si es la ciudad la que determina las prácticas sociales -como si esta fuese una suerte de estructura-, o si son estas las que determinan la forma de operar de la ciudad. Desde la óptica de Marx, es el régimen de producción el que determina las prácticas sociales -en cuanto permite la reproducción de los medios de vida-, sin embargo, las prácticas sociales son las que producen lo real, y por tanto, también este régimen de producción es un producto social. No obstante lo anterior, este régimen se ha ido transformando históricamente, llegando a ser un sistema de dominación que parece perpetuarse de forma indefinida. La vida ha sido reducida y sometida al imperio de la economía-política, es por ello que la praxis y la corporalidad también han padecido por la transformación real que esta impone, en tanto que utiliza procesos de subjetivación -la constitución del sujetopara reproducir su poderío, al mismo tiempo que utiliza a las imágenes - que transforman la naturaleza afectiva y potencial de los seres que la padecen- para determinar la acción y pasión de los individuos.

En el presente, se apela a una estética del hábitat que hace referencia a la estética de la praxis de los sentidos pero en el ámbito urbano, es decir, en la vida cotidiana bajo el alero del capitalismo, la que abarca la esfera de lo vivido, pero además, la esfera laboral del trabajo abstracto. Pareciera ser que ya no se habitan las ciudades, sino que solo se puede comprender el habitar como el hábitat, una visión restrictiva y coercitiva del primero, que apela tanto a la economía-política del espacio como a la ejercida en los cuerpos que lo habitan. El hábitat es comprendido por Henri Lefebvre como la 


\section{Daniela Cápona González.}

configuración espacial abstracta del capitalismo, en donde en su afán de homogeneización, atenta directamente contra la vida cotidiana, la que trastoca la naturaleza del hombre como ser-entre-objetos, para hacerlo un ser-entre-mercancías (Coccia, 2013, p. 13). Por ello el filósofo francés afirma:

En el reino del hábitat eso que era el habitar ha desaparecido del pensamiento, y se ha deteriorado fuertemente en la práctica (...). El hábitat, ideología y práctica, ha venido solo a reprimir las características elementales de la vida urbana, notadas por la ecología más superficial: la diversidad de los modos de vivir, los tipos urbanos, los paradigmas, modelos culturales y valores vinculados a las modalidades o modulaciones de la vida cotidiana. El hábitat se ha instaurado en una cima: aplicación de un espacio global homogéneo y cuantitativo, obligación hacia la "vida" de dejarse enclaustrar en cajas, jaulas o "máquinas de habitar" (Lefebvre, 1970, p. 110).

En este panorama se puede plantear la idea en donde hay, tanto en Spinoza como en Marx, apuntes para la consideración de una estética del hábitat, en cuanto que se trata de la forma en que, mediante los afectos, es decir, mediante la modificación de la potencia de obrar ejercida por una imagen de otro cuerpo, se impone una forma precisa de praxis que está siempre escindida del hombre. Si toda imagen modifica la naturaleza corpórea y cognitiva del hombre, y en la medida en que esta es fabricada por instituciones de tristeza que propician la impotencia con sucedáneos de alegría, entonces la forma en que el hombre actúa y padece, es decir, la forma en que este se exterioriza en el espacio, expresa también esta escisión. Pero incluso sobre la base de esta fabricación de impotencia, hay otro elemento que manifiesta de forma más radical esta escisión, que es precisamente el poder del dinero, en cuanto este ha adquirido un carácter cuasi ontológico. En este sentido, Scribano acierta al afirmar que: "la mistificación del capital, se vincula con la fuerza del dinero en re-emplazar las cualidades ontológicas de los hombres", se trata de un "Objeto que puede metamorfosearse en todos los objetos: el dinero" (Scribano, 2016, p.13). Lo que se condice con aquello que Spinoza había planteado ya en el siglo XVII. Spinoza utilizará a lo largo de su Ética solo una vez el concepto de dinero en E, IV. A. Cap. XXVIII, y será precisamente al momento de afirmar: "pero el dinero ha llegado a ser un compendio de todas las cosas, de donde resulta que su imagen suele ocupar el alma del vulgo con la mayor intensidad; pues difícilmente pueden imaginar forma alguna de alegría que no vaya acompañada como causa por la idea de la moneda" (p. 377). En este párrafo el filósofo holandés asocia no solo dinero y afectos -y por tanto, los conceptos de potencia, mente y cuerpo-, sino que además pone en evidencia que el deseo, en la medida en que está bajo el yugo del poder del dinero como compendio de todas las cosas, se torna una categoría óntica sujeta al orden de la mercancía -y ya no de los objetos esenciales-. Al mismo tiempo, y como afirma Mezzadra, esto implica que: 
Dinero y fuerza de trabajo no son, para él, solamente categorías económicas, son también categorías, por decirlo de algún modo, antropológicas (...). E indican, en particular, las dos modalidades esenciales a través de las que el individuo puede ser construido (producido) como propietario de sí. El campo de la subjetividad moderna aparece así, a través del análisis de Marx, irremediablemente (una vez más) como una escisión. A la potencia (fuerza de trabajo) se opone el poder (dinero) (Mezzadra, 2014, p. 89).

Se trata, por tanto, de un complejo escenario en el que ya no se puede hablar solo en términos de ideología como falsa conciencia, sino de una realidad que transforma la naturaleza del hombre. Ante la imposición de una estética del hábitat, lo que realmente está operando es una lógica de la impotencia revestida de afectos alegres, es decir, en palabras sencillas, de dominación. Es el cuerpo el que padece el influjo de estos afectos, los que en cuanto están estratégicamente dispuestos en un régimen económico -escindiendo la corporalidad respecto de sí misma, de su potencia y de su incidencia en el ámbito cognitivoque posibilita la potenciación de ciertos órganos -los del trabajo, generando su desmembramiento-, pero que niega la efectiva realización de esta potencia, porque el hombre ya no puede apropiarse de los objetos de una forma esencial, sino solo en la condición de extrañamiento a la que conduce la alienación. De allí las certeras palabras de Balibar cuando afirma que el capitalismo “(...) se manifestará como una asombrosa transformación de la impotencia en dominación: la abstracción de la conciencia, que traduce su incapacidad de actuar en la realidad (la pérdida de su "inmanencia"), se convierte en la fuente de un poder justamente porque está 'autonomizada"' (p. 54). Abstracción de la conciencia que se condice con la abstracción impuesta en el espacio, en cuanto que lo que los hombres "son coincide (...) con su producción, tanto con lo que producen como con el modo cómo producen" (Marx y Engels, 1970,pp. 19-20). Aquíradica la crítica de Lefebvre a la configuración abstracta del espacio y a la predominancia del logos, ya que la medida de la producción del espacio es el cuerpo, es por ello que si este está escindido, el espacio también lo estará.

En el principio fue el Topos. Antes, mucho antes del advenimiento del Logos (...). Mucho antes de que el espacio percibido por y para el "yo" se presentase como escindido y dividido, como esfera de tensiones y contactos simplemente virtuales y diferidos (...). Antes de la inteligencia analítica, que separa el intelecto, mucho antes que el conocimiento formal, hubo una inteligencia del cuerpo (Lefebvre, 2014, p. 240).

Si las prácticas espaciales determinan las configuraciones espaciales, y si, siguiendo a Marx y Engels, “(...) la verdadera riqueza espiritual del individuo depende totalmente de la riqueza de sus relaciones sociales (...)" (Marx y Engels, 1970, pp. 39), lo que hay que revitalizar para lograr la apropiación de la propia potencia es el vínculo 


\section{Daniela Cápona González.}

social esencial que define a lo humano, que es precisamente lo que ha sido escindido en virtud de la implementación de procesos de subjetivación que permiten reproducir el orden del capital. La vida cotidiana, en donde está puesta en juego la dialéctica espacial que Lefebvre identifica con lo percibido, lo concebido y lo vivido, ha sido puesta en pausa, atacando directamente el ámbito afectivo de lo vivido a partir de representaciones del espacio y el poder de los discursos. En los espacios de representación -que es en donde reside lo vivido- "se vive, se habla, tiene un núcleo o centro afectivo" (Lefebvre, 2013, p. 100), pues estos son los que configuran el habitar, refugio del valor de uso y la apropiación, pero que por lo mismo es constantemente atacado, doblegado, dominado, por lógicas afectivas e imaginativas por parte del capitalismo. Imponer de manera trascendental la economía-política sobre el espacio, implica reducir este a su aspecto cósico y material, en donde la arquitectura ha jugado un papel en contra, en cuanto que ha reproducido al ras de imagen material una monumentalidad fálica y vacía que procura representar el poder del capital, al mismo tiempo que, a nivel habitacional, ha instaurado edificaciones reducidas al funcionalismo. Contra esto, Lefebvre propone una arquitectura y economía del placer que busca la apropiación y restablecimiento del cuerpo en la escena filosófica y práctica.

Con el uso restaurado en su lugar propio, el espacio podría ser constituido sobre nuevas bases. Esto asume la existencia de un espacio del placer que es en nada parecido al espacio abstracto: espacio del desarrollo, que utiliza una excavadora para destruir todo aquello que podría resistir, pasiva o activamente. En este espacio, el estatuto del objeto puede ser determinado solo por su relación con el cuerpo y el estatuto del cuerpo: a ritmos, situaciones carnales (Lefebvre, 2014, p.135).

Para finalizar, en ambos filósofos se dan indicios para pensar cómo hoy se ha instaurado una estética del hábitat a partir de la imposición de dispositivos políticos e instituciones de fabricación de impotencia a partir de la estandarización de las prácticas sociales, es decir, de la sensibilidad y, por tanto, del cuerpo. Sin embargo, en esta estética del hábitat instaurada por el capitalismo caben líneas de fuga. Estas se fundamentan en la reapropiación de la praxis y del núcleo afectivo de la sociedad -lo vivido-, restaurando la potencia escindida del hombre hacia su actividad como ser genérico. Por eso el llamado de Marx en la famosa onceava tesis sobre Feuerbach: "Los filósofos se han limitado a interpretar el mundo de distintos modos; de lo que se trata es de transformarlo" (Fauerbach, 2006, p. 668). En la transformación de las prácticas sociales, en la reapropiación del cuerpo, la afectividad, la sensibilidad y lo social, está el punto de inflexión sobre el cual entablar una resistencia a las lógicas impositivas del capitalismo. La estética del hábitat debe ser reformulada para plantear un habitar verdadero en donde la potencia del hombre sea no solo para-sí, sino para-los-otros en su sentido social, en 
Para una estética de la vida cotidiana: Naturleza, potencia y cuerpo en Spinoza y Marx

donde su exteriorización a partir de la praxis de sí sea afirmación y potenciamiento de su ser genérico.

Proyecto de Investigación financiado por CONICYT-PFCHA/Doctorado Nacional/ 2018 -Folio 21181516, en el marco de la formación doctoral en el programa de Doctorado en Filosofía mención Estética y Teoría del Arte de la Universidad de Chile

\section{OBRAS CITADAS}

Agamben, Giorgio (2014). Desnudez. Buenos Aires: Adriana Hidalgo. Trad. de Mercedes Ruvituso, María Teresa D’Meza y Cristina Sardoy.

Balibar, Étienne (2000). La filosofía de Marx. Buenos Aires: Nueva visión.

Casanova, Carlos (2016). Estética y producción en Karl Marx. Santiago: Metales Pesados. Coccia, Emanuele (2013). El bien en las cosas. La publicidad como discurso moral. Cantabria: Asociación Shangrila Textos Aparte. Trad. de José Miguel Burgos Mazas.

Fernández, Osvaldo (2017). De Feuerbach al materialismo histórico. Una lectura de las tesis de Marx. Concepción: Perseo y Escaparate.

Feuerbach, Ludwig (2006). La esencia del cristianismo. Buenos Aires: Claridad. Trad. de Franz Huber.

Fischbach, Franck (2014). La production des hommes. Marx avec Spinoza. Paris: Vrin. Trad. del autor.

Lefebvre, Henri (2014). Toward an architecture of enjoyment. Minneapolis: University of Minnesota Press. Trad. del autor.

_ (2013). La producción del espacio. Madrid: Capitán Swing. Trad. Emilio Martínez Gutiérrez.

— (1970). La révolution urbaine. France: Éditions Gallimard. Trad. del autor.

Lordon, Frédéric (2015). Capitalismo, deseo y servidumbre. Marx y Spinoza. Buenos Aires: Tinta Limón, 2015. Trad. Sebastián Puente.

Marx, Karl (2011). "Sobre la cuestión judía". En Vernik, E. (Comp.). Volver a la cuestión Judía. Bensaïd, Bauer, Marx, Rosdolski, Rozitchner. Barcelona: Gedisa. Trad. Laura S. Carugatti.

(2010). Manuscritos de economía y filosofía. Madrid: Alianza, 2010. Trad. de Francisco Rubio Llorente.

(1970). “Tesis sobre Feuerbach". En Marx, C; Engels, F. La ideología alemana. Barcelona: Pueblos Unidos, Grijalbo. Trad. Wenceslao Roces. 
Marx, Karl y Engels, Friedrich (1970). La ideología alemana. Barcelona: Pueblos Unidos, Grijalbo. Trad. Wenceslao Roces.

Mezzadra, Sandro (2014). La cocina de Marx. El sujeto y su producción. Buenos Aires: Tinta Limón. Trad. de Diego Picotto.

Santos Herceg, José (2014). "Cotidianidad: Trazos para una conceptualización filosófica”. Alpha 38, 173-196.

Schmidt, Alfred (1977). El concepto de naturaleza en Marx. Madrid: Siglo XXI, 1977. Trad. de Julia M. T. Ferrari de Prieto y Eduardo Prieto.

Scribano, Adrian (2016). Sociología de las emociones en Carlos Marx. Raleigh, NC: A Contracorriente.

Spinoza, Baruch (2009). Ética. Madrid: Alianza. Trad. Vidal Peña. 